\title{
PERAN E- QUALITY SERVICE TERHADAP CITRA MEREK (STUDI PADA RUMAH SAKIT DI KOTA BANDUNG)
}

\author{
Anggono Raras Tirto Sakti ${ }^{1}$, Haripah Saulina Napitupulu ${ }^{2}$ \\ 1,2Program Studi Manajemen, STIE Indonesia Membangun, Bandung Indonesia \\ anggono72018@gmail.com ${ }^{1}$, Nhaylina1011@gmail.com ${ }^{2}$
}

\begin{abstract}
The target study is to analyze the e-service quality role on the brand image of Immanuel Hospital in Bandung. The electronic service quality is measured through the efficiency, responsiveness, compensation, and contact. the brand image is measured through the personality, reputation,value and corporate identity.The study method uses explanatory methods with data collection techniques through questionnaires and interviews. Population is customers Immanuel Hospital in Bandung. The customers number measuring are 1.500 with a proportional random sampling technique obtained by a sample of 100 customers. The data that has been collected is analyzed using a Likert scale system, and Structural Equation Modeling (SEM) Smart Partial Least Square (SmartPLS 3). The results showed that electronic service quality and the brand image by all indicators reliable and valid. The electronic service quality was significance influence to brand image. .
\end{abstract}

Keywords: electronic service quality; brand image; customer.

\begin{abstract}
Abstrak
Tujuan studi adalah untuk menganalisis peran kualitas layanan elektronik pada citra merek Rumah Sakit Immanuel di Bandung. Kualitas layanan elektronik diukur melalui efisiensi, daya tanggap, kompensasi, dan kontak. citra merek diukur melalui kepribadian, reputasi, nilai, dan identitas perusahaan. Metode penelitian menggunakan metode eksplanatori dengan teknik pengumpulan data melalui kuesioner dan wawancara. Populasi adalah pelanggan Rumah Sakit Immanuel di Bandung. Pengukuran jumlah pelanggan adalah 1.500 dengan teknik pengambilan sampel proporsional acak yang diperoleh dengan sampel 100 pelanggan. Data yang telah dikumpulkan dianalisis menggunakan sistem skala likert, dan Structural Equation Modeling (SEM) Smart Partial Least Square (SmartPLS 3). Hasil penelitian menunjukkan bahwa kualitas layanan elektronik dan citra merek oleh semua indikator dapat diandalkan dan valid. Kualitas layanan elektronik berpengaruh signifikan terhadap citra merek.
\end{abstract}

Kata Kunci: kualitas jasa elektronik; citra merek; pelanggan.

Corresponding author: Email : anggono72018@gmail.com

History of article : Received : Juli 2018 , Revised : September 2018, Published : November 2018 


\section{PENDAHULUAN}

Sebagai provinsi penyangga ibukota, maka selayaknya memiliki jumlah rumah sakit yang memadai untuk menampung kualitas kesehatan penduduknya. Secara nasional, jumlah penduduk Propinsi Jawa Barat menyumbang 18,34 persen dari penduduk nasional. Kemajuan teknologi internet saat ini sudah masuk ke dalam sektor kehidupan umat manusia. Sejalan dengan kebutuhan akan teknologi internet tersebut pada rumah sakit maka pada penelitian ini digunakan variabel laten e-quality service yang berperan dalam mempengaruhi variabel laten lainnya Citra merek.

E- quality service memiliki indikator efficiency (X1), responsiveness (X2), compensation (X3), contact (X4), Chase, Jacobs, \& Aquilano (2006), Ho dan Lee (2007). Citra merek memiliki indikator personality (Y1), reputation (Y2), value (Y3), corporate identity (Y4), Kotler dan Keller (2012).

\section{KAJIAN PUSTAKA}

Pemasaran adalah suatu fungsi organisasi dan serangkaian proses untuk menciptakan, mengkomunikasikan, dan memberikan nilai kepada pelanggan dan untuk mengelola hubungan pelanggan dengan cara yang menguntungkan organisasi dan pemangku kepentingannya, American Marketing Association (AMA). Keberhasilan suatu perusahaan dalam menjalankan organisasinya tidak lepas dari keberhasilan kinerja dari bagian marketing, Elbert dan Griffin (2009).

"Marketing is about identifying and meeting human and social needs. One of the shortest good definitions of marketing is meeting needs profitability", Kotler dan Keller (2016). Marketing adalah suatu proses sosial dan manajerial yang membuat individu dan kelompok memperoleh apa yang mereka butuhkan dan inginkan lewat penciptaan dan pertukaran timbal balik produk dan nilai dengan orang lain, Kotler dan Armstrong (2004).

Manajemen Pemasaran adalah kegiatan analisis, perencanaan, pelaksanaan, dan pengendalian berbagai program yang disusun dalam pembentukan, pembangunan, dan pemeliharaan laba hasil dari transaksi/ pertukaran melalui sasaran pasar untuk mencapai tujuan perusahaan dalam jangka waktu panjang, Sofjan Assauri (2013), Buchori dan Djaslim (2010), Saladin (2013).

Strategi pemasaran terdiri dari kegiatan pengambilan keputusan mengenai biaya pemasaran perusahaan, alokasi pemasaran, bauran pemasaran, keadaan lingkungan yang diharapkan termasuk kondisi persaingan yang dihadapi Kotler dan Keller, (2012), Assauri, (2014), David, (2012), McCarthy (2010).

Konsep pemasaran jasa dapat membedakan secara tegas antara barang dan jasa yang seringkali sukar dibedakan dalam implementasi pemasaran. Hal ini dikarenakan pembelian suatu barang seringkali disertai dengan jasa-jasa tertentu, dan sebaliknya pembelian suatu jasa seringkali juga melibatkan barang-barang yang melengkapinya, Kotler dan Keller (2016).

Pengertian jasa : "Services are identifiable, intangible activities that are the main object of transaction desaigned to provide want-satisfaction to customers. By this definition we exclude supplementary services that support the sale of goods or other services", Stanton (2012), Zeithaml dan Bitner (2010), Payne (2012).

Karakteristik jasa, tidak berwujud (intangibility), tidak dapat dipisahkan (inseparability), bervariasi (variability), dan tidak tahan lama (perishability), Kotler dan Keller (2016). Bauran Jasa terbagi menjadi lima kategori penawaran; Barang berwujud murni (pure tangible goods), barang berwujud yang disertai jasa (tangible goods with accompanying services), hibrida (Hybrid), jasa utama yang disertai dengan barang dan jasa kecil (major service with accompanying minor goods and services), dan jasa murni (pure service), Kotler dan Keller (2016), Lovelock dalam Tjiptono (2012).

\section{METODE PENELITIAN}

Metode penelitian menggunakan metode eksplanatori dengan teknik pengumpulan data melalui kuesioner dan wawancara. Populasi yang digunakan adalah 
pelanggan (pasien) Rumah Sakit Immanuel di Bandung. Pengukuran jumlah pelanggan adalah 1.500 dengan teknik pengambilan sampel proporsional acak yang diperoleh dengan sampel 100 pelanggan. Data yang telah dikumpulkan dianalisis menggunakan sistem skala likert, dan Structural Equation Modeling (SEM) Smart Partial Least Square (SmartPLS $3)$.

Desain penelitian yang dibuat seperti pada Gambar 1, Desain Penelitian.

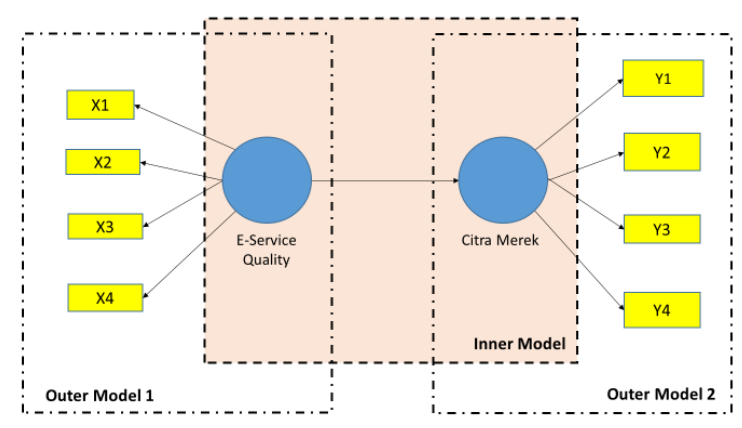

Gambar 1, Desain Penelitian.

Desain penelitian terdiri dari dua buah outer model, yaitu outer model 1, outer model 2, dan inner model. Outer model 1 merupakan hubungan antara variabel laten e-service quality dengan indikator indikator efficiency (X1), responsiveness (X2), compensation (X3), contact (X4). Outer model 2, merupakan hubungan antara variabel laten Citra merek terhadap indikator personality (Y1), reputation (Y2), value (Y3), corporate identity (Y4). Inner model merupakan hubungan antara variabel laten e-service quality dengan variabel laten citra merek.

Notasi hubungan indikator dan variabel laten disebut $\lambda$. Sehingga untuk outer model 1 terdapat $\lambda 1, \lambda 2, \lambda 3$, dan $\lambda 4$. Untuk outer model 2 terdapat $\lambda 5, \lambda 6, \lambda 7$, dan $\lambda 8$. Notasi hubungan antara variabel laten e-service quality dengan variabel laten disebut $\square$. Sedangkan notasi untuk varibel laten e-service quality disebut $\eta_{1}$, dan untuk varibel laten citra merek disebut $\eta_{2}$. Notasi kesalahan pada variabel laten citra merek $\zeta$.

Sehingga diperoleh persamaan SEM seperti berikut ini :

$$
\mathrm{Y}=\gamma \mathrm{X}+\zeta
$$

Hipotesa peneltian :

- H1 : E-quality servis berpengaruh terhadap Citra merek.

\section{HASIL DAN PEMBAHASAN}

Karakteristik responden dapat dibagi dalam empat kriteria, yaitu umur, pendidikan, gender, dan member (lamanya menjadi pasien di rumah sakit). Pada kriteria umur dibagi dalam empat kelompok besar, yaitu kelompok umur 25-35 ada 14 persen, 36-45 ada 36 persen, 46-55 ada 46 persen, dan 56-65 ada 4 persen. Kriteria pendidikan memiliki tiga kelompok pendidikan, yaitu SLTA/D3 ada 46 persen, S1 ada 35 persen, dan pasca sarjana ada 19 persen. Kriteria gender terdiri dari dua kelompok pria ada 34 persen. Kriteria member terdiri dari tiga kelompok, yaitu 1-3 tahun ada 27 persen, 4 tahun ada 21 persen, dan $>4$ tahun ada 52 persen, seperti terlihat pada Gambar 2, Karakteristik Responden.

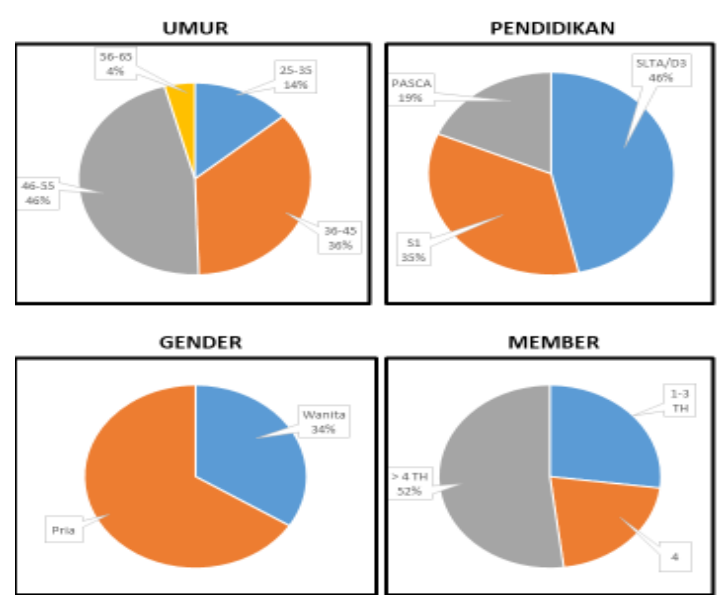

Gambar 2. Karakteristik Responden.

Hasil pengolahan data penelitian adalah seperti Gambar 3. Hasil Pengolahan Data Penelitian.

Uji konstruk reliabilitas berdasarkan hasil pengolahan data dengan aplikasi SmartPLS 3 diperoleh pada Cronbach's Alpha variabel laten citra merek sebesar 0.875 , dan variabel laten r-service quality sebesar 0.757 bila hasil pengukuran ini dibandingkan dengan standar yang dibutuhkan $>0.7$ maka artinya kedua 
variabel laten ini reliabel, perhatikan Tabel 1. Uji Konstruk Reliabilitas.

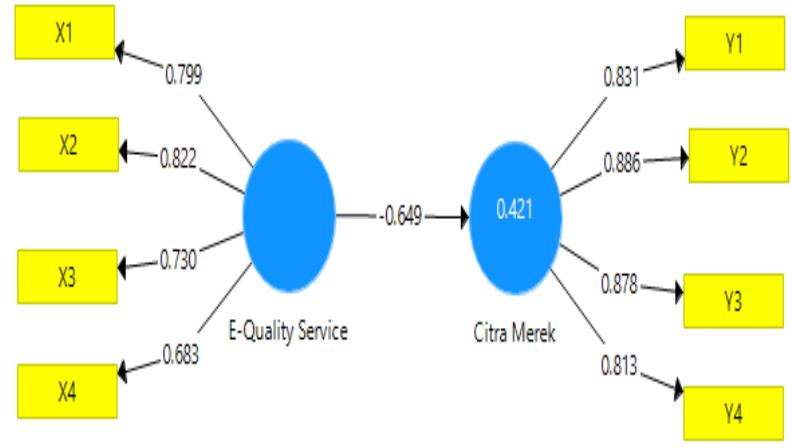

Gambar 3. Hasil Pengolahan Data Penelitian.

Tabel 1. Uji Konstruk Reliabilitas

\begin{tabular}{|c|l|c|c|c|}
\hline No. & Variabel Laten & Standar & Hasil & Ket \\
\hline 1 & Citra merek & \multirow{2}{*}{$>0.7$} & 0.875 & Reliabel \\
\cline { 1 - 1 } \cline { 5 - 6 } 2 & $\begin{array}{l}\text { E-quality } \\
\text { service }\end{array}$ & 0.757 & Reliabel \\
\hline
\end{tabular}

Uji konstruk validitas berdasarkan hasil pengolahan data dengan aplikasi SmartPLS 3 diperoleh pada Average Variance Extracted (AVE) variabel laten citra merek sebesar 0.727, dan variabel laten r-service quality sebesar 0.578 bila hasil pengukuran ini dibandingkan dengan standar yang dibutuhkan $>0.5$ maka artinya kedua variabel laten ini valid, perhatikan Tabel 2, Uji Konstruk Validitas.

Tabel 2. Uji Konstruk Validitas

\begin{tabular}{|c|l|c|c|c|}
\hline No. & \multicolumn{1}{|c|}{$\begin{array}{c}\text { Variabel } \\
\text { Laten }\end{array}$} & Standar & Hasil & Ket \\
\hline 1 & Citra merek & \multirow{2}{*}{$>0.5$} & 0.727 & Valid \\
\cline { 1 - 1 } 2 & $\begin{array}{l}\text { E-quality } \\
\text { service }\end{array}$ & 0.578 & Valid \\
\hline
\end{tabular}

Uji Collinearitas Statistik berdasarkan hasil pengolahan data diperoleh pada Collinearitas Statistik (VIF), inner VIF value sebesar 1.000, bila hasil pengukuran ini dibandingkan dengan standar yang dibutuhkan sebesar <5 maka artinya data terbebas dari multi collenearitas, perhatikan Tabel 3, Uji Collenearitas statistik.
Tabel 3. Uji Collenearitas Statistik (VIF)

\begin{tabular}{|c|l|l|c|c|}
\hline No. & $\begin{array}{c}\text { Variabel } \\
\text { Laten }\end{array}$ & Standar & Hasil & Ket \\
\hline 1 & $\begin{array}{l}\text { E-quality } \\
\text { service }\end{array}$ & 1.000 & $\begin{array}{c}\text { Bebas dari } \\
\text { multi } \\
\text { colleneariras }\end{array}$ \\
\hline
\end{tabular}

Uji besar pengaruh pada variabel laten citra merek dari variabel laten e-quality service sebesar 42,1 persen dapat dilihat pada $\mathrm{R}$ square, perhatikan Tabel 4, Uji R Square.

Tabel 4. Uji R Square

\begin{tabular}{|c|c|c|c|c|}
\hline No. & $\begin{array}{c}\text { Variabel } \\
\text { Laten }\end{array}$ & Standar & Hasil & Ket \\
\hline 1 & Citra merek & & 0.421 & $\begin{array}{c}\text { Sample } \\
\text { valid }\end{array}$ \\
\hline
\end{tabular}

Uji besar pengaruh variabel laten e-quality service terhadap variabel laten citra merek sebesar 0 persen dapat dilihat pada calculate boostrap Path Coefficients, pada $\mathrm{P}$ Values, diperoleh nilai 0.000 yang artinya variabel laten tersebut berpengaruh signifikan, perhatikan Tabel 5, Uji Path Coefficients.

Tabel 5. Uji Path Coefficients.

\begin{tabular}{|c|l|c|c|c|}
\hline No. & $\begin{array}{c}\text { Variabel } \\
\text { Laten }\end{array}$ & $\begin{array}{c}\text { Stand } \\
\text { ar }\end{array}$ & Hasil & Keterangan \\
\hline 1 & $\begin{array}{l}\text { E-quality } \\
\text { service } \rightarrow \\
\text { Citra merek }\end{array}$ & 0.000 & signifikan \\
\hline
\end{tabular}

Uji besar pengaruh variabel laten e-quality service terhadap variabel laten citra merek sebesar 0 persen dapat dilihat pada calculate boostrap, Path Coefficients, pada T Statistik, diperoleh nilai 9.813 yang artinya variabel laten tersebut berpengaruh signifikan, perhatikan Tabel 6, Uji Path Coefficients. Hal ini membuktikan bahwa hipotesa $\mathrm{H} 1$ diterima.

Tabel 6. Uji Path Coefficients.

\begin{tabular}{|l|l|l|l|}
\hline \multicolumn{1}{|c|}{$\begin{array}{c}\text { Variabel } \\
\text { Laten }\end{array}$} & Standar & Hasil & Keterangan \\
\hline $\begin{array}{l}\text { E-quality } \\
\text { service } \rightarrow> \\
\text { Citra merek }\end{array}$ & & 9.813 & signifikan \\
\hline
\end{tabular}

Uji Discriminant Validity ini dimaksudkan untuk mengetahui besarnya faktor loading masing-masing indikator pada variabel laten. Pada uji discriminant validity 
ini hasilnya terdiri dari antara lain cross loading. Pada cross loading dapat diketahui nilai faktor loading $\mathrm{X} 1=0.799, \mathrm{X} 2=0.822 . \mathrm{X} 3$ $=0.730$, dan $\mathrm{X} 4=0.683$. sedangkan nilai faktor loading $\mathrm{Y} 1=0.831, \mathrm{Y} 2=0.886, \mathrm{Y} 3=$ 0.878 , dan $\mathrm{Y} 4=0.813$. semua nilai loading faktor lebih besar dari nilai standar, yaitu 0.7. Namun pada X4 hasilnya adalah 0.683, kadang-kadang digunakan standar 0.6, maka X4 memenuhi syarat. Perhatikan Tabel 7, Uji Discriminant validity.

Tabel 7. Uji Discriminant Validity.

\begin{tabular}{|c|c|c|c|}
\hline $\begin{array}{c}\text { Variabel } \\
\text { Laten }\end{array}$ & Standar & Hasil & Ket \\
\hline $\begin{array}{l}\text { E-quality } \\
\text { service : }\end{array}$ & \multirow{10}{*}{$>0.7$} & & \multirow{10}{*}{ signifikan } \\
\hline $\mathrm{X} 1$ & & 0.799 & \\
\hline $\mathrm{X} 2$ & & 0.822 & \\
\hline X3 & & 0.730 & \\
\hline $\mathrm{X} 4$ & & 0.683 & \\
\hline Citra merek : & & & \\
\hline Y1 & & 0.831 & \\
\hline $\mathrm{Y} 2$ & & 0.886 & \\
\hline Y3 & & 0.878 & \\
\hline Y4 & & 0.813 & \\
\hline
\end{tabular}

\section{KESIMPULAN DAN SARAN}

Hasil penelitian yang telah dilakukan membuktikan bahwa peran e-quality service berpengaruh signifikan terhadap citra merek di Rumah Sakit Immanuel Bandung. Kondisi ini didukung oleh kedua variabel latennya yang reliabel,dan valid dalam penelitian. Kedua variabel penelitian sudah terbebas dari multi collenearitas,

Hasil penelitian ini bermanfaat bagi pengelola rumah sakit Immanuel dan rumah sakit lainnya dalam hal pengguanaan media sosial internet bagi pelayanan pelanggannya. Penggunaan variabel e-quality service dalam penelitian sebagai upaya memunculkan ide baru dalam internet marketing. Kemungkinan pengembangan penelitian yang bisa dilakukan kedepannya adalah melalui penambahan variabel penelitian lain yang dibutuhkan. Implikasi penelitian baik secara teoritis menambah wawasan bagi peneliti untuk masuk ke dunia internet.
Penelitian ini mempunyai keterbatasan yang dapat dianggap peluang bagi peneliti lainnya di masa depan. Keterbatasan pertama, penelitian ini antara lain hanya digunakan satu variabel eksogen e-quality service, perlu ditambah variabel eksogen lain. Keterbatasan kedua, jumlah rumah sakit yang diteliti perlu ditambah, dan keterbatasan ketiga, penelitian hanya pada pasien rawat jalan. Untuk penelitian berikutnya dapat dilakukan untuk pasien rawat inap.

\section{DAFTAR PUSTAKA}

Chase, Jacobs \& Aquilano. (2006). Internet Marketing : Measuring Service Quality: (2ed). Prentice Hall International, Inc. New Jersey.

Ho dan Lee. (2007). Internet Marketing : Aplication in Service Quality. Prentice Hall International, Inc. New Jersey.

Kotler\&Keller. (2012). Manajemen Pemasaran. Erlangga. Jakarta.

Assauri, Sofyan. (2008). Manajemen Pemasaran. Edisi 1. Cetakan Kedelapan. Grafindo Persada. Jakarta.

Cronin, J.J \& Taylor, S.A. (1992). Measuring Service Quality: A Reexamination and Extension. Journal of Marketing,(56), 55-68.

Flavian, C.et. al. (2005). The Influence of Corporate Image on Consumer Trust A Comparative Analysis in Traditional Versus Internet Banking. Internet Research. 15 (4). 44-47.

Hsu Mh, Chiu CM. (2004). Internet selfefficacy and electronic service acceptance. Decis.

Jefkins, Frank. (2003). Public Relations. Penerbit Erlangga. Jakarta.

Kotler, Philip \& Gary Armstrong. (2001). Prinsip-Prinsip Pemasaran. Jilid 1. Edisi Kedelapan. Penerbit Erlangga. Jakarta.

Kotler, Philip \& Gary Armstrong. (2004). Dasar-Dasar Pemasaran. Edisi Kesembilan. Jilid 1. Terjemahan Alexander Sindoro. Indeks. Jakarta.

Kotler, Philip \& Kevin Lane Keller. (2009). Manajemen Pemasaran. Edisi Ketiga Belas. Jilid 1. Jakarta. Erlangga. 
Lamb, Charles W, et al. (2007). Pemasaran Buku I. Edisi I. Salemba Empat. Jakarta.

Lovelock, H, Christopher \& Bitner. (2008). Services Marketing: Test, Cases and Reading. Prentice Hall. New Jersey.

Miles, Morgan P \& Jeffrey G. Covain. (2000). Corporate Image and Corporate Reputation in Customers Retention Decisions In Services. Journal of Retailing and Consumers Services, 8 (4).

Nirwana. (2006). Serice Marketing Strategy. Cetakan Pertama. Penerbit Dioma. Malang

Parasuraman, et, al., (1988). Konsep dan Teknik Pengukuran Kualitas Produk Jasa. Kajian Bisnis dan Manajemen, 4 (1), 55-56.

Payne, Adrian. (2001). The Essence of Services Marketing. Alih Bahasa Fandy Tjiptono. Cetakan Kedua. Andi Offset. Yogyakarta.

Tjiptono, Fandy. (2004). Manajemen Jasa. Edisi 1. Andi Offset. Yogyakarta. 
Journal IMAGE | Volume 7, Number 2, November 2018, page 45-50 
Journal IMAGE | Volume 7, Number 2, November 2018, page 45-50 
Journal IMAGE | Volume 7, Number 2, November 2018, page 45-50 
Journal IMAGE | Volume 7, Number 2, November 2018, page 45-50 